\title{
Sonographic biometry of spleen among school age children in Nsukka, Southeast, Nigeria
}

\author{
*Eze CU ${ }^{1}$, Agwu $\mathrm{KK}^{1}$, Ezeasor $\mathrm{DN}^{2}$, Ochie $\mathrm{K}^{1}$, Aronu $\mathrm{AE}^{3}$, Agwuna $\mathrm{KK}^{4}$, Nwadike $\mathrm{IU}^{1}$
}

1. Department of Medical Radiography and Radiological Sciences, Faculty of Health Sciences and Technology, University of Nigeria, Enugu Campus, Enugu State, Nigeria.

2. Department of Veterinary Anatomy, Faculty of Veterinary Medicine, University of Nigeria, Nsukka, Enugu State, Nigeria

3. Department of Paediatrics, Faculty of Medicine, University of Nigeria Teaching Hospital, Ituk-Ozalla, Enugu State, Nigeria

4. Department of Radiation Medicine, Faculty of Medicine, University of Nigeria Teaching Hospital, ItukOzalla, Enugu State, Nigeria

\begin{abstract}
Background: Normative value of spleen size among school age children is important for objective assessment of the spleen.

Objective: This study was aimed at determining sonographically the normal limits of the spleen size according to age, sex, and somatometric parameters among school age children.

Methods: A cross sectional study was done on 947 apparently healthy subjects (496 boys and 451 girls) aged $6-17$ years. The subjects were recruited from some primary and secondary schools within Nsukka metropolis and also from out patients in the study centre. A pilot study was done to determine the intra- and inter rater reliability of sonographic measurements of the spleen. The sonographic examination was performed on Shenzhen DP-1100 machine with 3.5 and $5 \mathrm{MHz}$ convex transducers. Spleen sizes were obtained with the subject in a right lateral decubitus position.

Results: Measurement of spleen length was reliable while measurement of spleen width was less reliable within and between sonographers. Dimensions of the spleen were not statistically different in boys and girls $(p>0.05)$. Height correlated best with spleen dimensions.

Conclusion: Normogram of the spleen size with respect to height is important in the determination of some pathology associated with changes in its size.
\end{abstract}

Keywords: Ultrasound; measurements; spleen size; school age children.

African Health Sciences 2013; 13(2): 384 - 392 http://dx.doi.org/10.4314/ahs.v13i2.27

\section{Introduction}

Measurement of spleen size is important because many disorders present with enlargement or reduction of the spleen. Serial size measurements may be used in tracking normal growth pattern of the spleen and in the follow-up of known pathology of the spleen in children. Establishment of normal values of the spleen in routine sonographic

*Corresponding author:
Dr Eze Charles Ugwoke
Department of Medical Radiography and
Radiological Sciences
Faculty of Health Sciences and Technology
University of Nigeria, Enugu Campus
Enugu State, Nigeria
Tel: +2348052805214
Email: ugwoke.eze@unn.edu.ng,
ezecharlesu@yahoo.com

examinations can serve as a base line for diagnosis of endemic diseases in the locality associated with changes in its size such as lymphoma, sickle cell disease and tropical splenomegaly syndrome including malaria. The critical functions performed by the spleen also necessitate its sonographic biometry.

The morphological characterization of the spleen is one of the many parameters that assist in detecting splenic disorders and systemic infections, inflammatory and malignant pathologies. Invariably the complete characterization of the disease process may need morphological assessment of anatomical structures and laboratory reports. However, there are many conditions where organomegaly may be the only feature on ultrasonography like splenomegaly in malaria. On the contrary, clinically palpable spleen may not be pathological. Pushed down spleen due 
to subdiaphragmatic pathology, visceroptosis and palpable spleen in $10 \%$ to $15 \%$ of normal children are a few examples of palpable spleen without any clinical significance ${ }^{1}$. Clinical assessment of changes in visceral organ size is difficult and unreliable ${ }^{2}$.

Radiography, computed tomography and radionuclide imaging expose the patients to ionizing radiation while magnetic resonance imaging is expensive and is not readily available in developing countries $^{3}$. Sonography is a simple and reliable way to visualize and measure abdominal visceral organs without the risk of ionizing radiation. Ultrasonography is a non-invasive, established, safe, quick and accurate method for measurement of liver and spleen size ${ }^{4}$. Refinements in ultrasound technology have advanced the use of this modality beyond the simple display of anatomy, anatomic relationships, and spatial localization of lesions. Sonography is also useful in the determination of agenesis, hypertrophy, atrophy, and / or ectopic location of visceral organs. In cases of gross enlargement of visceral organs such as the spleen, confirmation by sonography is easy. However, where there is only mild enlargement of the spleen as in malaria and typhoid fever, making decisions about the size can be difficult. Therefore, it is very important to have a set of standard normal sonographic values showing upper and lower limits.

In many countries with endemic schistosomiasis, abdominal ultrasonography is used for organometric investigations of the spleen and liver and has been shown to be reliable and reproducible ${ }^{5}$. In Nigeria too, ultrasonography can be used in epidemiological studies of many endemic diseases like chronic malaria and typhoid fever, provided we have normative data. So far we do not have any normative data on spleen size in a large population of school age children from our country.

Organ volumes obtained by using various organ dimensions and body surface areas are already used in correlation with body parameters to describe the normal dimensions and to measure the degree of pathologic deviations from normal ${ }^{6}$. However, these volume measurement techniques are time consuming and impractical in daily use. Therefore, use of length, width and or antero- posterior dimensions seems more practical for purpose of establishing normograms. Any other data, like age, body weight and height which are easily obtainable can be combined with the above measurements when necessary.
Generally, in clinico-radiological practice, there is paucity of data on normal spleen dimensions and its variants for the interpretation of sonographic examinations in school age children. Moreover, racial differences in the normal length and width of the spleen have been shown to exist ${ }^{7}$. This research could, therefore, be related and introduced into a more diverse population by ensuring population specific charts to compensate for demographic variations in spleen dimensions.

In order to establish our own standards and suggest upper limits and to provide additional data to the literature on this subject, the main purpose of present study is to determine the normal limits and variations of the spleen dimensions in relation to age, sex, height, weight, body surface area (BSA) and body mass index (BMI) among healthy school age children in a Nigerian population. The provision of these data in the present study will enable a more practical and objective evaluation during a sonographic examination involving the spleen of school age children.

\section{Methods}

The study was carried out using a cross sectional research design and convenience sampling method at University of Nigeria Nsukka Medical Centre between January 2010 and May 2011.

\section{Sample size}

These include Igbo school age children aged 6 to 17 years. The age of each subject was obtained from his/her hospital birth certificate. Some of the children attended hospital for clinical reasons while majority of them attended hospital just as volunteers for the study.

\section{Selection criteria}

Volunteers and outpatients were examined by a pediatrician and those who met the following selection criteria were enlisted in the study.

\section{Exclusion criteria}

Subjects with tropical splenomegaly syndrome (malaria and typhoid fever), lymphadenopathy, sickle cell disease, obesity, splenic parenchymal mass lesions, accessory spleen and cysts were excluded as normal subjects because of possible enlargement or reduction of the spleen. 


\section{Inclusion criteria}

Subjects with no history of malaria, typhoid fever, malnutrition, sickle cell disease or obesity and subjects with no evidence of splenic parenchymal mass lesions, abnormal echotexture of the spleen, accessory spleen and cysts were included as normal subjects.

\section{Ethical Approval}

Ethical approval was obtained from the Ethics Committee of the University of Nigeria Nsukka Medical Centre. In addition informed consent was obtained from each participant's parent before data collection began. A chaperon was available during data collection on female subjects.

\section{Equipment}

The sonographic examinations were performed with high resolution real time scanner (DP-1100, Shenzhen Mindray Biomedical Electronics Co. Ltd, China) manufactured in 2008 with $3.5 \mathrm{MHz}$ and $5 \mathrm{MHz}$ convex transducers. Using the available freeze-frame capability, all the sonographic measurements were made with curvilinear probes using the electronic calipers.

Demographic data were collected on each participant at the time of their pre-participation physical examination. This information included age, sex, height and body weight whereas BSA and BMI were computed from measured height and weight. Body mass index was calculated by BMI = weight $(\mathrm{Kg}) /$ height $\left(\mathrm{m}^{2}\right)$ while BSA was calculated by BSA= "weight $x$ height $/ 3600^{11}$. Anthropometric measurements were obtained on the participants wearing light weight street clothes without shoes. Weight was measured on a calibrated portable Salter scale (BR 9011; Hana Co. Ltd, China) to the nearest $0.1 \mathrm{~kg}$. Height was measured with a metal tape measure to the nearest $0.5 \mathrm{~cm}$ with the participants standing upright with the head in the Frankfurt position $^{8}$.

\section{Scanning technique}

A coupling medium was first applied to the area being scanned to ensure good transmission of the ultrasound beam into the subjects.

The technique of right lateral decubitus position in the coronal plane was adopted for this study because of superior advantage of obtaining easily the longest dimension of the spleen and reproducibility of measurement ${ }^{4,6,10}$.

Longitudinal size measurement was performed between the most superomedial and the most inferolateral points of the spleen. The transverse dimension was measured between the hilum and the most superolateral margin of the spleen. The choice of probe depends on the age and physique of the subjects.

A subgroup of twenty participants underwent two ultrasound scans of the organs done two days apart by two different sonographers to determine intraand inter rater reliability of spleen size measurements (pilot study). The sonographers have 14 years of experience in abdominal sonography. One of these sonographers did all the scanning for the main study. Spleen dimensions were measured three times, and the mean values were recorded. All measured spleen for the subjects had normal position, shape and echotexture. The measurement of spleen dimensions were made during deep inspiration.

\section{Statistical analysis}

Association between spleen dimensions and sex, age, height, weight, BSA, and BMI was assessed with Pearson's correlation coefficient; to determine the exact pattern of the relationship, non-linear regression analysis was performed. Analysis of variance (polynomial linear) and minimum norm quadratic unbiased estimation methods were used to calculate the variance and co-variance of the correlation estimates. Linear regression analysis was used to create models for calculating normative values. Difference of continuous variables between two independent groups was assessed with the Student's t-test while more than two groups were assessed with analysis of variance (ANOVA). Intra class correlation coefficients (ICCS) were calculated to assess inter- and intra rater reliability for ultrasound measurement of the spleen, using SPSS statistical package version 10.14 (SPSS Chicago, Illinois, USA). Statistical significance was considered at $\mathrm{p}<0.05$. Descriptive statistical methods were used when appropriate.

\section{Results}

Table 1 shows intra- and inter rater reliability in the measurement of spleen dimensions. The intra- and inter variability coefficients in the measurement of spleen length are 0.88 and 0.84 respectively while that of spleen width are 0.63 and 0.60 respectively. The mean values of the spleen length and width in the entire population studied are $91.03 \pm 10.72 \mathrm{~mm}$ and $47.63 \pm 5.21 \mathrm{~mm}$ respectively. The mean values of the body parameters include: age $=11.66 \pm 3.37$ years; height $=140.24 \pm 17.93 \mathrm{~cm}$; weight $=34.88$ $\pm 12.23 \mathrm{~kg} ; \mathrm{BSA}=1.16 \pm 0.28 \mathrm{~cm}^{2}$ and $\mathrm{BMI}=$ $17.10 \pm 2.06 \mathrm{~kg} / \mathrm{m}^{2}$. 
Table 1: Intra- and Inter rater reliability of Sonographic measurement of Spleen size

\begin{tabular}{|c|c|}
\hline Observer & $\begin{array}{l}\text { Intra- and Inter rater } \\
\text { reliability }\end{array}$ \\
\hline Intraobserver & Intra rater reliability \\
\hline Sonographer 1 & $\begin{array}{l}\text { Length }=\operatorname{ICC}(2,1)=0.86 \\
\text { Width }=\operatorname{ICC}(2,1)=0.58\end{array}$ \\
\hline Intraobserver, & Intra rater reliability \\
\hline Sonographer 2 & $\begin{array}{l}\text { Length }=\operatorname{ICC}(2,1)=0.90 \\
\text { Width }=\operatorname{ICC}(2,1)=0.68\end{array}$ \\
\hline Interobserver, & Inter rater reliability \\
\hline Both Sonographers & $\begin{array}{l}\text { Length }=\operatorname{ICC}(2,1)=0.84 \\
\text { Width }=\operatorname{ICC}(2,1)=0.6\end{array}$ \\
\hline
\end{tabular}

ICC $=$ Intra class correlation coefficient; $\operatorname{ICC}(2,1)$ $=$ Intra class correlation coefficient between the first and second measurements obtained by each sonographer (intra observer) and between the first measurements obtained by both sonographers (interobserver)

The age versus sex distribution of the normal subjects $(\mathrm{n}=947)$ studied is shown in table 2 . There are 496 $(52.4 \%)$ males and $451(47.6 \%)$ females. No statistically significant differences were found in the spleen dimensions between male and female $(p>$ 0.05). Therefore all data were arranged without being separated according to sex. Figure 1 shows how the sonographic measurements of spleen dimensions were obtained.

Table 2: Age and Sex distribution of the normal subjects

\begin{tabular}{|c|c|c|c|c|}
\hline \multirow[t]{2}{*}{$\overline{\mathrm{S} / \mathrm{N}}$} & \multirow[t]{2}{*}{ Age (years) } & \multicolumn{2}{|c|}{ Sex } & \multirow[t]{2}{*}{ Total } \\
\hline & & Male & Female & \\
\hline 1 & 6 & 43 & 31 & 74 \\
\hline 2 & 7 & 39 & 26 & 65 \\
\hline 3 & 8 & 27 & 45 & 72 \\
\hline 4 & 9 & 39 & 26 & 65 \\
\hline 5 & 10 & 70 & 24 & 94 \\
\hline 6 & 11 & 62 & 23 & 85 \\
\hline 7 & 12 & 25 & 47 & 72 \\
\hline 8 & 13 & 43 & 64 & 107 \\
\hline 9 & 14 & 38 & 49 & 87 \\
\hline 10 & 15 & 38 & 32 & 70 \\
\hline 11 & 16 & 47 & 20 & 67 \\
\hline 12 & 17 & 25 & 64 & 89 \\
\hline Total & 496 & 451 & 947 & \\
\hline
\end{tabular}

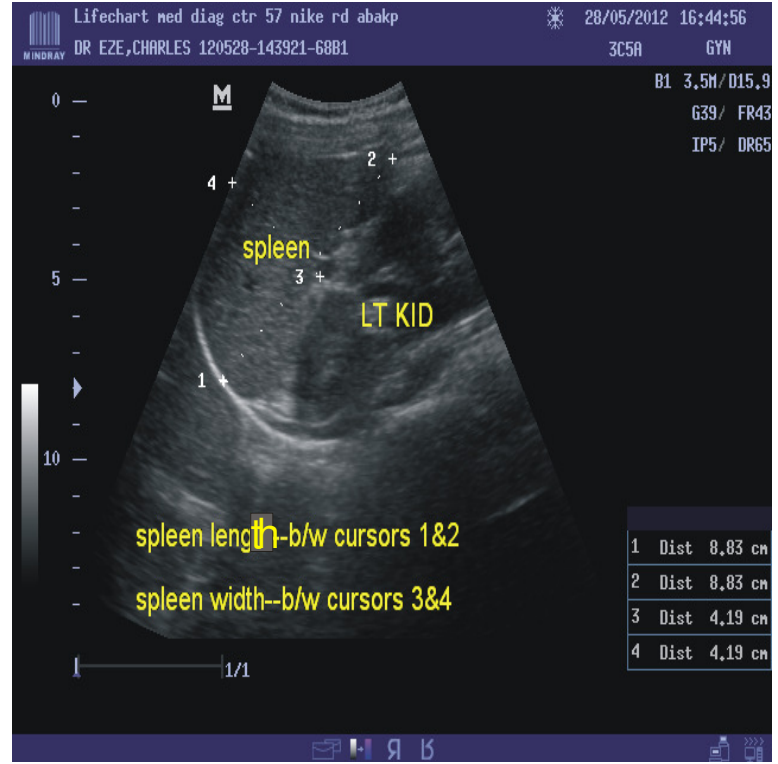

Figure 1: Sonogram showing measurement of the longitudinal length of the spleen performed between the most superomedial and the most superolateral margin of the spleen.

The transverse width was measured between the hilum and the most superolateral margin of the spleen.

Table 3 shows Pearson's correlation coefficient of spleen size with body parameters. Among the body parameters height was the one best correlated with the spleen dimensions. Height, weight, age and BSA correlated strongly with spleen size while BMI showed moderate correlation.

Table 3: Pearson's Correlation coefficient of Spleen dimensions with body Parameters

\begin{tabular}{ll}
\hline $\begin{array}{l}\text { Body } \\
\text { parameter }\end{array}$ & $\begin{array}{l}\text { Correlation coefficient of } \\
\text { spleen dimensions }\end{array}$ \\
\hline Age & $\begin{array}{l}\text { Length; } r=0.854(p<0.05) \\
\text { Width; } r=0.821(p<0.05)\end{array}$ \\
Height & $\begin{array}{l}\text { Length; } r=0.888(p<0.05) \\
\text { Width; } r=0.834(p<0.05)\end{array}$ \\
Weight & $\begin{array}{l}\text { Length; } r=0.883(p<0.05) \\
\text { Width; } r=0.822(p<0.05)\end{array}$ \\
BMI & Length; $r=0.698(p<0.05)$ \\
& Width; $r=0.627(p<0.05)$ \\
BSA & Length; $r=0.878(p<0.05)$ \\
& Width; $r=0.823(p<0.05)$ \\
\hline
\end{tabular}


The suggested normal limits of spleen dimensions with respect to subjects' height are shown in tables 4 . The 3rd percentile values represent the range of borderline lower limit of normal; the $3 \mathrm{rd}-97^{\text {th }}$ percentile values represent the range of normal values whereas the $97^{\text {th }}$ percentile values represent the range of borderline upper limit of normal.

Table 4: Normal limits of spleen length with respect to height

\begin{tabular}{|c|c|c|c|c|c|c|c|c|c|}
\hline \multirow{3}{*}{$\begin{array}{l}\text { Subjects } \\
\text { Body } \\
\text { height } \\
(\mathrm{cm})\end{array}$} & \multirow{3}{*}{$\mathbf{N}$} & \multicolumn{4}{|c|}{ Longitudinal Length $(\mathrm{mm})$ of Spleen } & \multirow{3}{*}{$3 \%$} & \multirow{3}{*}{$97 \%$} & \multirow{2}{*}{\multicolumn{2}{|c|}{$\begin{array}{c}\text { Suggested Limits of } \\
\text { Normal }\end{array}$}} \\
\hline & & \multirow[t]{2}{*}{ Minimum } & \multirow[t]{2}{*}{ Maximum } & \multirow[t]{2}{*}{ Mean } & \multirow[t]{2}{*}{ SD } & & & & \\
\hline & & & & & & & & Lowermost & Uppermost \\
\hline $102-107$ & 14 & 67 & 75 & 70.3 & 2.3 & 67.0 & 75.0 & 62 & 80 \\
\hline $108-113$ & 46 & 70 & 87 & 76.3 & 3.6 & 70.4 & 85.4 & 65 & 90 \\
\hline 114-119 & 80 & 71 & 88 & 79.4 & 4.1 & 72.0 & 87.0 & 68 & 95 \\
\hline $120-125$ & 70 & 72 & 92 & 81.1 & 4.9 & 72.0 & 90.0 & 68 & 100 \\
\hline $126-131$ & 105 & 74 & 95 & 86.5 & 4.9 & 75.0 & 94.0 & 70 & 105 \\
\hline $132-137$ & 134 & 79 & 113 & 88.8 & 4.4 & 81.0 & 96.9 & 75 & 108 \\
\hline $138-143$ & 106 & 79 & 103 & 91 & 5.1 & 81.2 & 101.8 & 75 & 110 \\
\hline 144-149 & 91 & 78 & 103 & 90.4 & 4.5 & 79.8 & 97.2 & 76 & 111 \\
\hline $150-155$ & 66 & 81 & 105 & 95 & 6.4 & 89.0 & 105.0 & 78 & 112 \\
\hline 156-161 & 89 & 87 & 116 & 97 & 8.1 & 87.0 & 112.3 & 82 & 118 \\
\hline $162-167$ & 66 & 95 & 117 & 107.5 & 6.5 & 95.0 & 116.0 & 90 & 120 \\
\hline $168-173$ & 74 & 97 & 116 & 106.5 & 5 & 101.0 & 115.8 & 92 & 120 \\
\hline 174-179 & 11 & 113 & 116 & 114.1 & 1.1 & 113.0 & 116.0 & 105 & 122 \\
\hline
\end{tabular}

Figures 2 and 3 show the percentile curves of longitudinal length and transverse width of the spleen versus subjects' height.

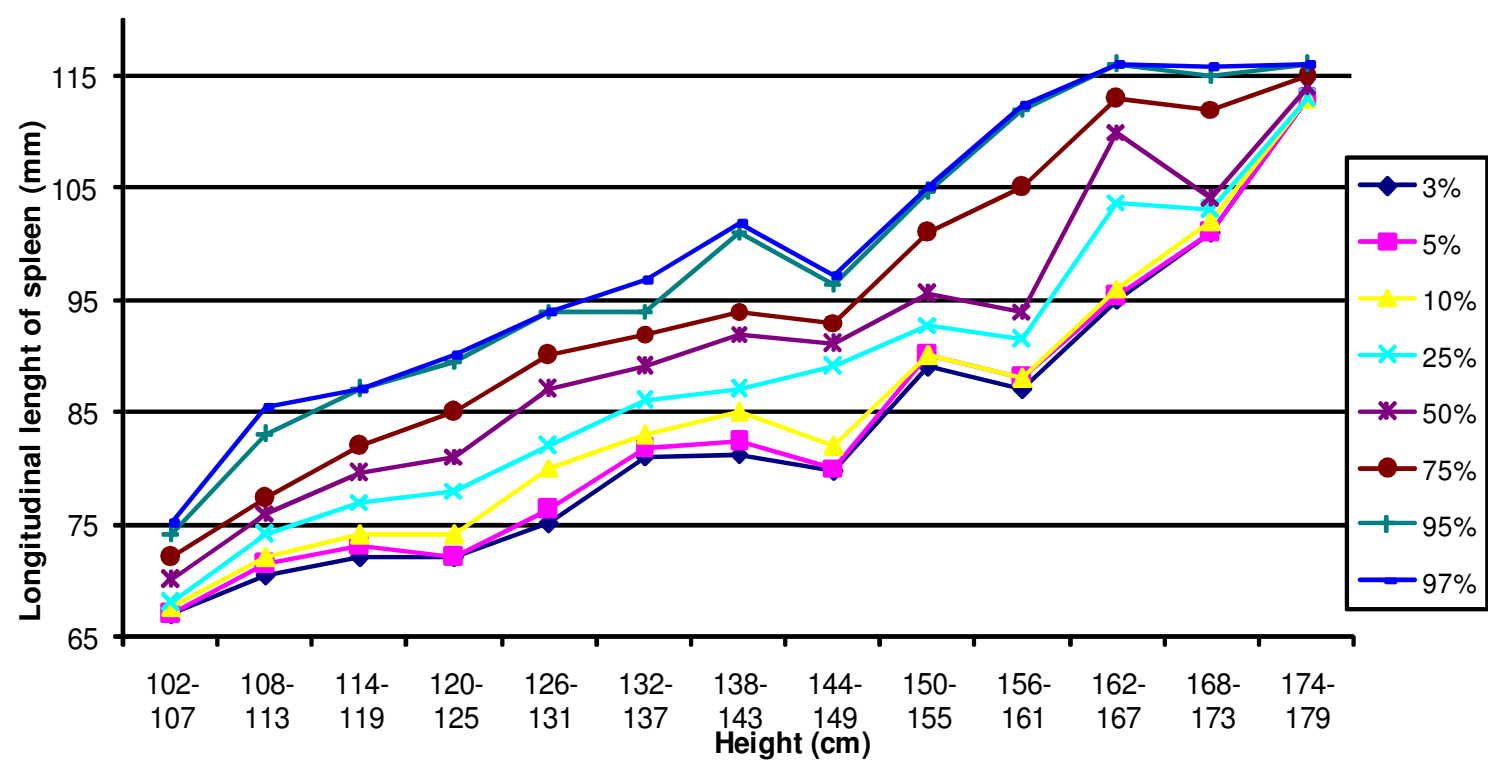

Figure 2: Percentile curve of longitudinal length of the spleen versus height 


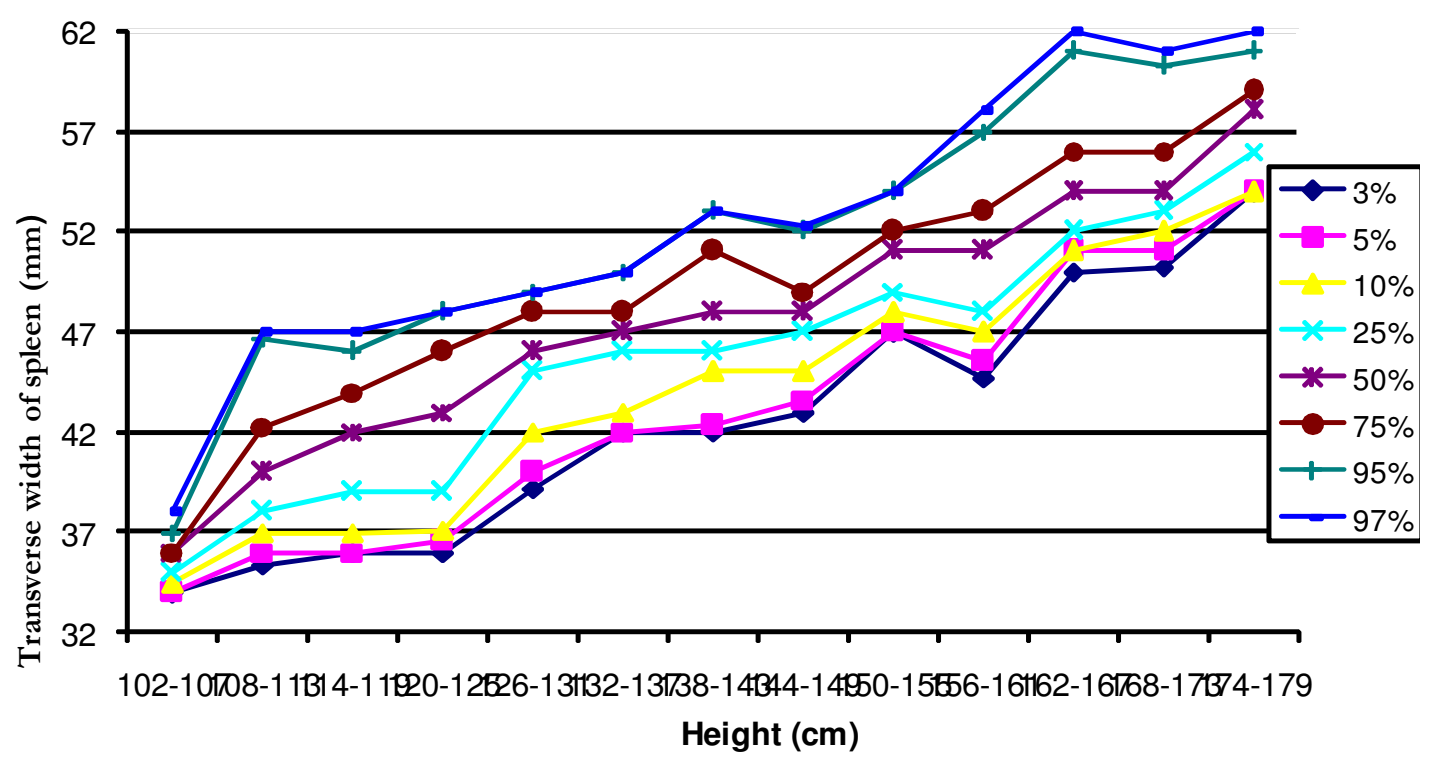

Figure 3: Percentile curve of transverse width of the spleen versus height

Figure 4 and 5 show scatter diagrams of length and width of the spleen plotted against height of subjects respectively indicating positive linear relationships. The prediction models of normal spleen size are: spleen length $(\mathrm{mm})=0.518 \times$ Height $(\mathrm{cm})+18.29$ and spleen width $(\mathrm{mm})=0.242 \times$ Height $(\mathrm{cm})+$ 13.65 .

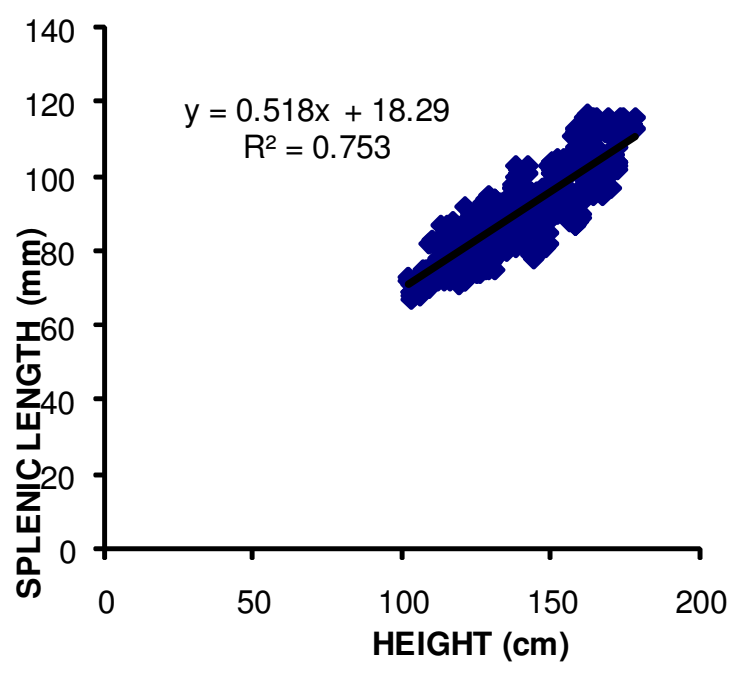

Figure 4: Scatter diagram of longitudinal dimension of the spleen plotted against heights of subjects

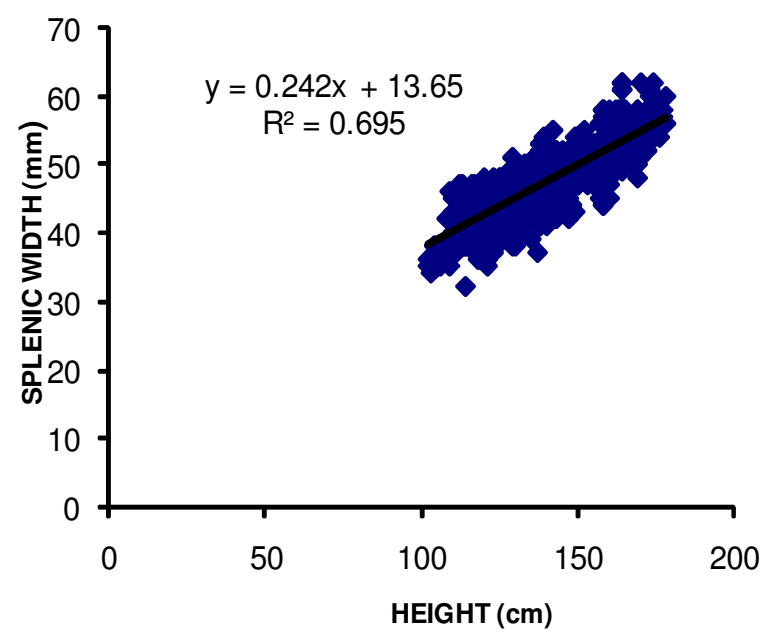

Figure 5: Scatter diagram of transverse dimension of the spleen plotted against heights of subjects

\section{Discussion}

The normal values of the spleen dimensions are important parameters during sonographic examinations ${ }^{12,13}$. There are different methods for evaluating the spleen by sonography such as supine, left anterior oblique and right lateral decubitus positions. A right lateral decubitus position in the coronal plane was mostly preferred in previous studies because of superior advantage of obtaining easily the longest dimension of the spleen and reproducibility of measurement ${ }^{4,6,10}$. Accordingly, a 
right lateral decubitus position in the coronal plane was used as the plane of measurement in this study and strong correlations were found with the body parameters. This result is in accordance with the findings of Konus et $\mathrm{al}^{6}$.

In this study, spleen size was analyzed in terms of length and width which are simple, reproducible, reliable and objective measurements. Measurement of spleen length was reliable within and between sonographers as shown by high intraand inter rater reliability in this study. Measurement of spleen width was, however, less reliable as evidenced by only moderate intra- and inter rater reliability in this study. These findings support the historical assessment of visceral organ size based on longitudinal length measurement. Because the measurement of spleen width is less reliable, defining splenomegaly on the basis of spleen volume may be more uncertain.

The scan and measurements in this study were performed by a certified and an experienced sonographer to reduce inter-observer errors. A previous study has shown that experience has an influence on measurement accuracy during ultrasound scanning ${ }^{14}$. To minimize intra- observer errors, organ dimensions were measured three times and the mean values were recorded.

In this study, school age children ranging from 6 17 years were studied. This age range of 6-17 years of the studied subjects is in keeping with school-age children in Nigeria ${ }^{15}$. Nigerian children have specific issues relating to spleen size because of malaria, typhoid fever, malnutrition and environmental issues which increase spleen size compared to the rest of the developed world. To the best of the authors' knowledge, literatures reviewed showed that this study covers the largest series of paediatric spleen dimensions by sonography involving the age range of 6-17 years in any Nigerian population.

There were no significant differences in the measured spleen size with respect to sex $(p>0.05)$. This finding is similar to the findings of other previous authors ${ }^{6,16}$. Therefore, sex certainly is not a determining factor for spleen dimension in schoolage children in this population. This suggests that special tables based on gender are not necessary.

Spleen dimensions increased with increase in age in the studied population. There was also significant increase in the spleen dimensions with increase in height, body weight and BSA. However, there was a moderate increase in BMI as spleen dimensions increased. Previous studies are in agreement with these findings ${ }^{6,12,16}$. These findings indicate that spleen length and width can be used as growth parameters in school age children.

The morphology of visceral organs varies from person to person. During the maturation process from infancy through adolescence, growth of visceral organs shows a high correlation with gains in height, weight and BSA ${ }^{4,6}$. Notably, height, weight, BSA, and age were highly correlated with spleen dimensions while BMI showed moderate correlation with spleen dimensions in this study. Among the body parameters, height was the one best correlated with the spleen dimensions followed by weight, BSA, age and BMI. Compared with the transverse dimension, longitudinal dimension of the spleen showed the highest correlation with the body parameters. These results were also supported by the variance and covariance of the correlation coefficients. These observations probably result from rapid body growth that occurs before the attainment of mature body morphology at adult stage. Thus it is easy to predict spleen size reliably on the basis of these variables especially height in this population. Konus et $\mathrm{al}^{6}$ also reported that spleen dimensions showed the best correlation with body height in a children population. Soyupak et $\mathrm{al}^{16}$ and Safak et $\mathrm{al}^{10}$, however, reported that spleen dimensions showed the best correlation with body weight among children population they studied. Thus the normal limits and percentile curves of the spleen among school age children were defined according to body weight in a Turkish population ${ }^{10}$. These differences with present study may be due to variations in race or different ethnic origins.

There is no consensus on which measurement parameter is most sensitive for investigating the normal limits of organ dimensions as these parameters might show variations in different ethnic origins ${ }^{10}$. Although weight and age showed high correlation with organ dimensions in present study, they are not as important as height and body surface area. Body surface area also showed a high correlation with organ dimensions, but to a lesser degree compared to height. Moreover, the derivation of BSA is not as practical as height. For these reasons, present study preferred not to use BSA in standard tables and graphics. Therefore, when deciding if sonographically obtained dimensions of the spleen is normal in school age children in this studied population, height should be the primary concern. 
Present study preferred to define the lowermost and uppermost longitudinal dimensions of the spleen with respect to height using the $3^{\text {rd }}$ and $97^{\text {th }}$ percentile values respectively as a guide. In most other studies, sizes between the $5^{\text {th }}$ and $95^{\text {th }}$ percentiles were the accepted normal limits ${ }^{17}$. However, this practice results in approximately $10 \%$ of children with normal visceral organs falling outside these limits ${ }^{18}$. Besides, although plus or minus two standard deviations are the accepted equivalents of the $5^{\text {th }}$ and $95^{\text {th }}$ percentile values statistically ${ }^{19}$, some studies were based on plus or minus one standard deviation ${ }^{20}$. Other previous studies established normal percentiles of the spleen according to age $\mathrm{e}^{6}$, ${ }^{16}$. This definition according to age also differs from the present study's definition according to height and may be due to differences in the socio-demographic characteristics of the studied population as well as racial variations. El Sharkawy et $\mathrm{al}^{21}$ also found that Egyptian normogram for ultrasound organometry of the liver is different from those of other countries and suggested that each country should have their own population specific normograms for this organ. Data of normal visceral organ sizes according to age have been given in tabular form in previous studies $^{22}$. In other studies data were given only in graphic form ${ }^{23}$. In this study data were presented both in tabular and graphic forms (scatter diagram and percentile curves) with the aim of enabling a more practical evaluation during a sonographic examination. This presentation is in agreement with previous studies ${ }^{6,10}$.

The following prediction model of the longitudinal length and transverse width of the spleen, in millimeters, were built according to height in this study as an alternative method for the examiners: Spleen length $(\mathrm{mm})=0.518 \times$ Height $(\mathrm{cm})+18.29$ and spleen width $(\mathrm{mm})=0.242 \times$ Height $(\mathrm{cm})+$ 13.65. Thus if the height is obtained in a busy practice or in remote locations where ultrasound facility is not readily available, the normal spleen size for school age children in this population can be estimated from this equation.

The implication from our study for the Nigerian ultrasound community is obvious because of possible variations in the anthropometric parameters of various populations, races and regions. It is important for Nigerians to have their own population specific normograms of the spleen in the studied age group as Americans and Europeans' population data cannot be used as universal patterns. Our results could be extrapolated to the wider international community where there is need for each country to establish their own population specific normograms of the spleen size in school age children with reference to the body parameter that shows the best correlation with spleen dimensions as height might show variations in different ethnic origins or races.

\section{Study limitations}

The study was done in the Southeast geopolitical region of Nigeria which is inhabited by people of Igbo ethnic background. A multicentre study in other regions of the country might improve the precision of the estimates and also the generalizability of the data. Furthermore, the socio economic status of the children studied was not recorded. It is hoped that further studies will address these limitations.

\section{Conclusion}

To the best of our knowledge, this is the first study in Nigeria which defined normative values for the spleen size in a large cohort of school age children aged 6 - 17 years representing a diverse population with regard to body morphology. Data was presented in tabular and graphic forms with the aim of enabling a more practical evaluation during a sonographic examination.

Acknowledgements: Many thanks to the director, medical and paramedical staff of University of Nigeria Medical Centre Nsukka for providing the enabling support for the study.

\section{Recommendations}

1. The established normal parameters can be used to determine the pathologic changes in the size of the spleen in routine sonographic examination of school age children in this population.

2. The prediction model of the normal spleen dimensions can serve as an alternative method for sonographers assessing spleen size in a busy practice setting or in remote locations in the studied population.

3. The methods of measurement and analysis used in this study are standardized and easy to apply. Findings are handy and reliable and are suitable particularly for sonography units and paediatric departments with large numbers of patients.

4. Any specific longitudinal dimension of the spleen should primarily be correlated with patient height and findings should be compared with tables and graphics of normal parameters. 


\section{References}

1. Camitta BM. Splenomegaly. In: Kliegman RM, Behrman RE, Jenson HB, Staton BF. Eds. Nelson Textbook of Pediatrics. $18^{\text {th }}$ ed. Philadelphia, Pa: Saunders; 2007. p.2091.

2. Tamayo SG, Richman LS, Mathews WC et al. Examiner dependence on physical diagnostic tests for the detection of splenomegaly: a prospective study with multiple observers. Journal of General Internal Medicine 1993; 8: 69-75.

3. Joshi R, Singh A, Jajoo N, Pai M, Kalantari SP. Accuracy and reliability of palpation of the liver in detecting hepatomegaly: a rural hospital based study. Indian Journal of Gastroenterology 2004; 23: 171-174.

4. Megremis SD, Vlachonikolis IG, Tsilimigaki AM. Spleen length in childhood with US: normal values based on age, sex, and somatometric parameters. Radiology 2004; 231:129-134.

5. Yazdanpanah Y, Thomas AK, Kardorff R, Talla I, Sow S, Niang M, et al. Organometric investigations of the spleen and liver by ultrasound in Schistosoma mansoni endemic and non-endemic villages in Senegal. American Journal of Tropical Medicine and Hygiene1997; 57: 245-249.

6. Konus OL, Ozdemir A, Akkaya A, Erba G, Celik H, Isik S. Normal liver, spleen and kidney dimension in neonates, infants and children: evaluation with sonography. American Journal of Roentgenology 1998; 171:1693-1698.

7. Hosey RG, Mattacola CG, Kriss V, Armsey T, Quarles DJ, Jagger J. Ultrasound assessment of spleen size in collegiate athletes. British Journal of Sports Medicine 2006; 40:251-254.

8. Norton K and Olds I (eds). Anthropometrica. A textbook of body measurement for sports and health course. Sydney: University of New South Wales Press. 1996; PP 25-73.

9. Sarac K, Kutlu R, Yakinci C, Durmaz Y, Baysal T, Ozgen U. Sonographic evaluation of liver and spleen size in school- age children. Turkish Journal of Medical Sciences 2000; 30:187-190.

10. Safak AA, Simsek E, Bahcebasi T. Sonographic assessment of the normal limits and percentile curves of liver, spleen and kidney dimensions in healthy school-aged children. Journal of Ultrasound Medicine 2005; 24(10): 1359-1364.

11. Mostelled RD. Simplified calculation of body surface area (letter). New England Journal of Medicine 1987; 317: 1098.

12. Mittal R, Chowdhary DS. A pilot study of the normal measurements of the liver and spleen by ultrasonography in the Rajasthani population.
Journal of Clinical and Diagnostic Research 2010; 4(4): 2733-2736.

13. Dhingra B, Sharma S, Mishra D, Kumari R, Pandey RM, Aggarwal S. Normal values of liver and spleen by ultrasonography in Indian children. Indian Pediatrics 2010; 47: 487-492.

14. Eze CU, Ezugwu FO, Agbo, JA. Sonographic determination of fetal gender in the second and third trimesters in a private hospital in Enugu, southeast, Nigeria. Radiography 2010; 16(4): 292296.

15. Ogunfowora OB, Olanrewaju DM, Akenzua GI. A comparative study of academic achievement of children with sickle cell anemia and their healthy siblings. Journal of National Medical Association 2005; 97(3); 405-408.

16. Soyupak SK, Narli N, Yapicioglu H, Satar M, Sungur EH. Sonographic measurements of the liver, spleen and kidney dimensions in the healthy term and preterm newborns. European Journal of Radiology 2002; 43:73-78.

17. Schlesinger AE, Edgar KA, Boxer LA. Volume of the spleen in children as measured on CT scans: normal standards as a function of body weight. American Journal of Roentgenology 1993; 160:11071109.

18. Zerin JM, Blance CE. Sonographic assessment of renal length in children: a reappraisal. Paediatric Radiology 1994; 24:101-106.

19. Remington RD, Schork MA. Statistics with application to the biological and health sciences, $2^{\text {nd }}$ ed. Eaglewood Cliffs, NJ: Prentice Hall. 1985; Pp 23-43.

20. Dremsek PA, Kritscher H, Bohm G, Hochberger O. Kidney dimensions in ultrasound compared to somatometric parameters in normal children. Paediatric Radiology 1987; 17: 285-290.

21. El Sharkawy E., Faris R, Grumbach K, Edelman $\mathrm{R}$, Clemens $\mathrm{T}$, Rao $\mathrm{M}$, Darwish $\mathrm{M}$. Ultrasonographic measurement of the normal liver and spleen among Egyptians 10 - 50 years old. Journal of Egyptians Public Health Association 1997; 72 (3 - 4): 257 - 283.

22. Rosenberg HK, Markowitz RI, Kolberg H, Park C, Hubbard A, Bellah RD. Normal splenic size in infants and children: sonographic measurements. American Journal of Roentgenology 1991; 157:119-12.

23. Dittrich M, Milde S, Dinkel E, Baumann W, Weitzel D. Sonographic biometry of liver and spleen size in childhood. Paediatric Radiology 1983; 3:206-211. 